\title{
Amniotic fluid index, non-stress test and color of liquor: as a predictor of perinatal outcome
}

\section{Ruma Sarkar Anand*, Preeti Singh, Renu Sangal, Reena Srivastava, Neela Rai Sharma, Harish Chandra Tiwari}

Department of Obstetrics and Gynaecology, B. R. D. Medical College, Gorakhpur, Uttar Pradesh, India

Received: 05 August 2016

Accepted: 06 September 2016

\section{*Correspondence:}

Dr. Ruma Sarkar Anand,

E-mail: rumasarkaranand@gmail.com

Copyright: (c) the author(s), publisher and licensee Medip Academy. This is an open-access article distributed under the terms of the Creative Commons Attribution Non-Commercial License, which permits unrestricted non-commercial use, distribution, and reproduction in any medium, provided the original work is properly cited.

\section{ABSTRACT}

Background: The universal aim of maternity care provision is birth of a healthy baby to a healthy mother. All birth attendants strive to achieve a good standard of care during labor to prevent an outcome such as 'birth asphyxia'. The aim was to study the role of AFI, NST and color of liquor in predicting perinatal outcome in term pregnancy in active labor.

Methods: Prospective observational study of in women 18-35 years of age in active Labor admitted in department of Obstetrics and Gynecology BRD Medical College Gorakhpur, India.

Results: In patient with AFI $<5 \mathrm{~cm}, 83 \%$ needed intervention during labor (77\% LSCS, 6\% instrumental vaginal delivery) and $89 \%$ newborn had APGAR <7, while in AFI $>5 \mathrm{~cm}$ group only $29 \%$ needed intervention (24\% LSCS, $5 \%$ instrumental vaginal delivery) and only 20\% newborn had APGAR <7. Normal NST (Cat.-I) group had $89 \%$ normal vaginal delivery and only $11 \%(9.5 \%$ LSCS, $1.5 \%$ instrumental vaginal delivery) needed intervention with $6 \%$ newborn with APGAR $<7$ at 1 minute (' $p$ ' $<0.00001$ ), while pathological NST (Cat.-III) group had $16 \%$ normal vaginal delivery and $84 \%$ (8\% instrumental vaginal delivery, $76 \%$ LSCS) needed intervention during labor with $92 \%$ newborn with APGAR $<7$ at 1 minute ('p'<0.00001). Clear liquor group had $85 \%$ had normal vaginal delivery and only $15 \%$ needed intervention (14\% LSCS, $1 \%$ instrumental vaginal delivery) with $8.3 \%$ newborn with APGAR $<7$ at 1 minute, while meconium stained liquor group only $6.5 \%$ had normal vaginal delivery and $93.5 \%$ needed intervention (16\% instrumental vaginal delivery, $77.5 \%$ LSCS) with $87 \%$ newborn with APGAR $<7$ at 1 minute.

Conclusions: AFI, NST and color of liquor can effectively detect fetal distress already present at admission, thereby avoiding unnecessary delay and decrease in decision to delivery time and improve fetal outcome.

Keywords: Aminiotic fluid index, Non-stress test, Color of liquor, Perinatal outcome

\section{INTRODUCTION}

Pregnancy is one of the life's most exciting and fulfilling adventures. The birth process or labor is like a rebirth for every woman. The universal aim of maternity care provision is birth of a healthy baby to a healthy mother. All birth attendants strive to achieve a good standard of care during labor to prevent an outcome such as 'birth asphyxia'(policy statement 1996) and avoid its short or long term consequences (Mac Lennan) for the child., However, despite best efforts, occurrences of birth asphyxia continue to happen in obstetric practice. ${ }^{1}$

Worldwide, the WHO estimates that between 4-9 million newborns suffer birth asphyxia each year (Vikram et al). ${ }^{3}$ Of these about 1 million infants die and a similar number survive with long-term disabilities related to birth injury (Eerden PV et al) asphyxia. ${ }^{4}$ Various ante-partum surveillance techniques (Penna L.) have been developed 
for prompt detection and management of obstetric complications. ${ }^{5}$ But in developing countries like INDIA where workload is more and resource settings are low, we need techniques which are simple, cost-effective, easy to use and less time consuming.

Estimation of amniotic fluid index (Phelan JP et al, Tom $\mathrm{C}$ et al, Callen PW) during ultrasonography is a major step for prediction of pregnancy outcome while electronic fetal monitoring (RCOG Guideline 2001) is the most widely used technique for assessing fetal well-being in Labor. ${ }^{6,9,10}$ So AFI estimation with non-stress test at admission and assessment of color of liquor (Schultz M et al) at rupture of membranes-these three parameters altogether can be used as a valuable screening test to detect fetal distress (ACOG Practice Bulletin No 106, 2009 ) as early as possible and prevent fetal morbidity as well as mortality. ${ }^{11,12}$

\section{METHODS}

This prospective observational study was done on 206 pregnant women with term pregnancy (37 weeks to 41.6 weeks) in active labor admitted in labor room of department of obstetrics and gynecology, Nehru Chikitsalya, BRD Medical College, Gorakhpur, Uttar Pradesh from September 2014- October 2015 for a period of 12 months.

\section{Inclusion criteria}

All pregnant women of gestational age 37- 41.6 weeks in active labor b/w 18-35 years of age.

\section{Exclusion criteria}

- Multiple pregnancies.

- Pregnancy with gestational age $<37$ weeks.

- Premature rupture of membranes.

- Congenital anomalies.

- Non-cephalic presentations/malpresentations.

- Previous LSCS.

- Intrauterine death.

- LSCS done for maternal indication (cephalopelvic disproportion ante-partum hemorrhage, ante-partum eclampsia).

\section{Method of collection of data}

After taking written and informed consent and fulfilling the inclusion criteria, patients were included in the study.

\section{Method of study}

Detailed antental history including presence of high risk factors was elicited from the patient, then they were clinically examined and subjected to ultrasonograhy for AFI estimation in the following manner (Magann EF). ${ }^{13}$
- Patient laid in supine position.

- A linear, curvilinear, or sector transducer can be used.

- Uterus divided into four quadrants using the maternal sagittal midline vertically, and the upper edge of the uterine fundus.

- The transducer must be kept parallel to the maternal sagittal plane and perpendicular to the maternal coronal plane throughout.

- The deepest cord free and clear pocket of amniotic fluid is visualized, and the image frozen. The ultrasound calipers were manipulated to measure the pocket in a strictly vertical direction.

- The process was repeated in each quadrant and the pocket measurements summed=AFI.

If the AFI is $<8 \mathrm{~cm}, 4$ quadrant evaluation was performed 3 times and average was taken.

After AFI estimation, non-stress test was done and color of liquor was noted during spontaneous or artificial rupture of membranes. Progress of Labor was monitored with partogram and mode of delivery, perinatal outcome (APGAR score of at $1 \mathrm{~min}$ and NICU admission), condition of neonate and mother were noted at the end of each delivery.

\section{RESULTS}

Depicts the distribution of amniotic fluid index, NST and color of liquor among 206 patients studied. 82\% (170) had AFI $>5.00 \mathrm{~cm}$ but $<24.00 \mathrm{~cm}$, while $18 \%$ (36) had AFI $<5.00 \mathrm{~cm}$ i.e. they fall in oligohydramnios group (Table 1).

Table 1: Distribution of amniotic fluid index, nonstress test at admission and color of liquor.

\begin{tabular}{|c|c|c|c|}
\hline \multirow{2}{*}{$\begin{array}{l}\text { Amniotic } \\
\text { fluid index } \\
(\text { Total=206) }\end{array}$} & \multicolumn{3}{|c|}{$<5.00 \mathrm{~cm}>5.00 \mathrm{~cm}$ but $<24 \mathrm{~cm}$} \\
\hline & $\begin{array}{l}36 \\
(17.84 \%)\end{array}$ & $170(82.52 \%$ & \\
\hline \multirow{2}{*}{$\begin{array}{l}\text { Non-stress test } \\
\text { at admission } \\
\text { (Total=206) }\end{array}$} & Normal & Intermediate & Pathological \\
\hline & 126 & 30 & 50 \\
\hline \multirow{2}{*}{$\begin{array}{l}\text { Color of } \\
\text { Liquor } \\
(\text { Total=206) }\end{array}$} & Clear & $\begin{array}{l}\text { Meconium } \\
\text { thick }\end{array}$ & $\begin{array}{l}\text { Meconium } \\
\text { thin }\end{array}$ \\
\hline & $\begin{array}{l}144 \\
(69.90 \%)\end{array}$ & $\begin{array}{l}36 \\
(17.47 \%)\end{array}$ & $\begin{array}{l}26 \\
(12.62 \%)\end{array}$ \\
\hline
\end{tabular}

Out of 206 patients enrolled $61 \%$ had normal (Cat-I), $14.5 \%$ had suspicious/ indeterminate (Cat-II), while $24 \%$ had pathological/abnormal (Cat-III) tracings.

Out of 206 patients enrolled 144 (70\%) had clear liquor while 62 (32\%) had meconium stained liquor. 36 (thick) and 26 (thin).

Table 2 shows correlation of AFI with other study variables which is as follows: 


\section{In the oligohydramnions group $(<5 \mathrm{~cm})$}

- $66 \%$ patients were in the age group 18-25 years, $66 \%$ patients were unbooked,61\% were primigravida

- $73 \%$ had abnormal/pathological NST at admission, $62 \%$ had meconium stained liquor during Labor, $16 \%$ delivered vaginally while $83 \%$ needed intervention

- $\quad 89 \%$ newborn had APGAR score $<7$ and hence NICU admission in comparison to $20 \%$ in normal liquor group

- Newborn mortality in oligohydramnios group was $6 \%$ while $2 \%$ in normal liquor group.

Table 2: Correlation of study variables according to amniotic fluid index.

\begin{tabular}{|c|c|c|c|}
\hline & Amniotic & 1 index & \\
\hline & $<5.0 \mathrm{~cm}(\%)$ & $\begin{array}{l}>5.0 \mathrm{~cm} \\
(\%)\end{array}$ & \\
\hline Age & & & \\
\hline$-18-25$ years & $24(66.0)$ & $130(76.0)$ & $\begin{array}{l}=1.92 \\
-2\end{array}$ \\
\hline$-26-30$ years & $09(25.0)$ & $33(19.0)$ & $\begin{array}{l}\mathrm{df}=2 \\
\mathrm{n}=0382\end{array}$ \\
\hline$-31-35$ years & $03(09.0)$ & $07(05.0)$ & \\
\hline Booking status & & & $\chi^{2}=12.2$ \\
\hline - Booked & $16(44.0)$ & $126(74.0)$ & $\mathrm{df}=1$ \\
\hline - Unbooked & $20(66.0)$ & $44(26.0)$ & $\mathrm{p}=0.000$ \\
\hline Parity & & & $\chi^{2}=6.73$ \\
\hline - Primi- & $22(61$ & $64(38.0)$ & \\
\hline - Multi-gravida & $14(39.0)$ & $106(62.0)$ & $\mathrm{p}=0.010$ \\
\hline Non-stress test & & & \\
\hline - Normal & $06(16.0)$ & $120(70.0)$ & \\
\hline - Intermediate & $04(11.0)$ & $26(16.0)$ & 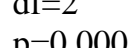 \\
\hline - Abnormal & $26(73.0)$ & $24(14.0)$ & \\
\hline Color of liquor & & & $\chi^{2}=19.9$ \\
\hline - Clear & $14(38.0)$ & $130(76.0)$ & \\
\hline - Meconium & $22(62.0)$ & $40(24.0)$ & $\mathrm{p}=0.000$ \\
\hline Mode of delive & & & \\
\hline $\begin{array}{l}\text { - Normal } \\
\text { vaginal } \\
\text { discharge }\end{array}$ & $06(16.0)$ & $120(70.0)$ & $\begin{array}{l}\chi^{2}=40.6 \\
\mathrm{df}=2\end{array}$ \\
\hline - Instrumental & $02(05.5)$ & $10(05.8)$ & \\
\hline - LSCS & $28(77.5)$ & $40(23.5)$ & \\
\hline Apgar score & & & $\chi^{2}=64.8$ \\
\hline$-<7$ & $32(89.0)$ & $34(20.0)$ & \\
\hline$->7$ & $04(11.0)$ & $136(80.0)$ & $\mathrm{p}=0.000$ \\
\hline Condition of bab & y discharge & & $\chi^{2}=1.80$ \\
\hline - Satisfactory & $34(94.0)$ & $167(98.2)$ & $\mathrm{df}=1$ \\
\hline - Unsatisfactory & $02(06.0)$ & $03(01.8)$ & $\mathrm{p}=0.179$ \\
\hline
\end{tabular}

- Pathological NST was more associated with oligohydramnios group $(<5 \mathrm{~cm})-72 \%$ versus only $14 \%$ in normal AFI group.

- Pathological NST group- 76\% LSCS, $16 \%$ vaginal delivery, and $8 \%$ instrumental vaginal delivery, while normal NST group had $9.5 \%$ LSCS, $1.5 \%$ instrumental vaginally delivery, and $88 \%$ vaginal delivery.

Table 3: The correlation of NST (at admission) with other study variables.

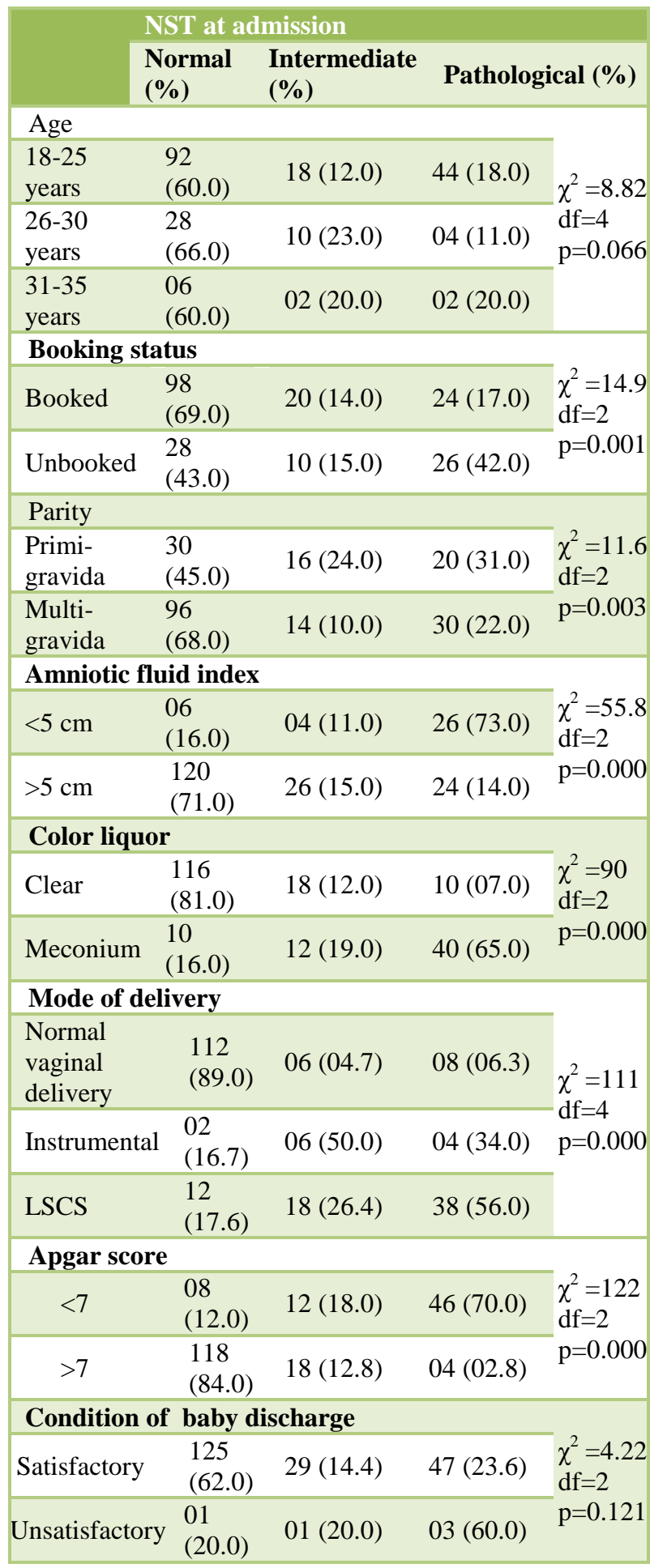

- Normal NST group had 6\% APGAR <7 (at 1 minute), 94\% APGAR >7. Pathological NST had $92 \%$ APGAR $<7$ and $8 \%>7$. So there was significant difference in neonatal outcome in the two groups. 
Table 4 shows the correlation of study variables (AFI, NST and color of liquor) with perinatal outcome (in terms of mode of delivery and newborn APGAR score at 1 minute).

Table 4: Correlation of mode of delivery and neonatal outcome (in terms of APGAR score at $1 \mathrm{~min}$ ).

\begin{tabular}{|c|c|c|c|c|c|c|c|}
\hline & \multicolumn{4}{|c|}{ Mode of delivery } & \multicolumn{3}{|c|}{ APGAR score at $1 \mathrm{~min}$. } \\
\hline & $\begin{array}{l}\text { Normal } \\
\text { delivery } \\
(\%)\end{array}$ & $\begin{array}{l}\text { Instrumental } \\
\text { vaginal } \\
\text { delivery }(\%)\end{array}$ & $\begin{array}{l}\text { LSCS } \\
(\%)\end{array}$ & & $<7(\%)$ & $>7(\%)$ & \\
\hline AFI & & & & \multirow{3}{*}{$\begin{array}{l}\chi^{2}=40.6 \\
d f=2 \\
p=0.000\end{array}$} & & & \multirow{3}{*}{$\begin{array}{l}\chi^{2}=64.8 \\
d f=1 \\
p=0.000\end{array}$} \\
\hline$<5 \mathrm{~cm}$ & $06(17.0)$ & $02(05.5)$ & $28(77.0)$ & & $32(89.0)$ & $04 \quad 11.0)$ & \\
\hline$>5 \mathrm{~cm}$ & $120(71.0)$ & $10(05.8)$ & $40(23.5)$ & & $34(20.0)$ & $136(80.0)$ & \\
\hline NST & & & & \multirow{4}{*}{$\begin{array}{l}\chi^{2}=111 \\
d f=4 \\
p=0.000\end{array}$} & & & \multirow{4}{*}{$\begin{array}{l}\chi^{2}=122 \\
\mathrm{df}=2 \\
\mathrm{p}=0.000\end{array}$} \\
\hline Normal (category-I) & $112(89.0)$ & $02(1.58)$ & $12(09.5)$ & & $08(06.4)$ & $1183.6)$ & \\
\hline Intermediate (category-II) & $06(20.0)$ & $06(20.0)$ & $18(60.0)$ & & $12(40.0)$ & $1860.0)$ & \\
\hline Pathological (category-III) & $08(16.0)$ & $04(08.0)$ & $38(76.0)$ & & $46(92.0)$ & $04(08.0)$ & \\
\hline Color of liquor & & & & \multirow{3}{*}{$\begin{array}{l}\chi^{2}=113 \\
\mathrm{df}=2 \\
\mathrm{p}=0.000\end{array}$} & & & \multirow{3}{*}{$\begin{array}{l}\chi^{2}=123 \\
\mathrm{df}=1 \\
\mathrm{p}=0.000\end{array}$} \\
\hline Clear & $122(85.0)$ & $02(01.0)$ & $20(14.0)$ & & $12(08.4)$ & $1321.6)$ & \\
\hline Meconium stained & $04(06.5)$ & $10(16.0)$ & $48(77.4)$ & & $54(87.0)$ & $08(13.0)$ & \\
\hline
\end{tabular}

In patient with AFI $<5 \mathrm{~cm}, 83 \%$ needed intervention during labor $(77 \%$ LSCS, $6 \%$ instrumental vaginal delivery] and $89 \%$ newborn had APGAR $<7$, while in AFI $>5 \mathrm{~cm}$ group only $29 \%$ needed intervention $(24 \%$ LSCS, 5\% instrumental vaginal delivery) and only $20 \%$ newborn had APGAR $<7$.

Normal NST (Cat.-I) group had 89\% normal vaginal delivery and only $11 \%$ [9.5\% LSCS, $1.5 \%$ instrumental vaginal delivery] needed intervention with $6 \%$ newborn with APGAR $<7$ at 1 minute (' $p$ ' $<0.00001)$, while pathological NST (Cat.-III) group had $16 \%$ normal vaginal delivery and $84 \%$ (8\% instrumental vaginal delivery, $76 \%$ LSCS) needed intervention during Labor with $92 \%$ newborn with APGAR $<7$ at 1 minute ('p'<0.00001).

Clear liquor group had $85 \%$ had normal vaginal delivery and only $15 \%$ needed intervention (14\% LSCS, $1 \%$ instrumental vaginal delivery) with $8.3 \%$ newborn with APGAR $<7$ at 1 minute, while meconium stained liquor group only $6.5 \%$ had normal vaginal delivery and $93.5 \%$ needed intervention (16\% instrumental vaginal delivery, $77.5 \%$ LSCS) with $87 \%$ newborn with APGAR $<7$ at 1 minute.

\section{DISCUSSION}

The findings of (Table 1) regarding AFI has been found to be similar to the study by Syeda Azra Tasneem et al, where $20 \%$ were in oligohydramnios $(<5.0 \mathrm{~cm}$ AFI $)$ group, $21 \%$ in border line oligo group (5.1-8.0 cm AFI) while $59 \%$ were in normal AFI group $(>8 \mathrm{~cm}) .{ }^{14}$ In the study by Bhagat $\mathrm{M}$ et al, $12.5 \%$ had AFI $<5.00 \mathrm{~cm}$, while $87.5 \%$ had AFI $>5.00 \mathrm{~cm}$, similarly in the study by
Alchalabi HA et al, 37\% patients had AFI $<5.00 \mathrm{~cm}$ while $63 \%$ had AFI $>5.00 \mathrm{~cm}^{15,16}$

Our findings regarding NST has been found to be similar to the study by Lohana RU et al, where $85 \%$ had reactive and $15 \%$ had non-reactive NST at admission. ${ }^{17}$ In the study by Shreshtha P et al Cat.-I is 77\%, Cat.-II 9\%) and Cat.-III $20 \%$ while in the study by Rahman $\mathrm{H}$ et al; Cat.-I is $77.0 \%$, Cat.-II 14\%) and Cat.-III $9 \% .^{18,19}$

Observation regarding color of liquor found to be comparable to studies by Becker $\mathrm{S}$, where prevalence was $10 \%$, Ziadeh SM et al also had prevalence of $11 \%$, while Maymon E et al in the study had $17 \%$ prevalence and Nathan et al in their study had prevalence of $20 \% .^{21-23}$

In the oligohydramnios $(<5 \mathrm{~cm})$ group, there was significant association with pathological NST at admission, meconium stained liquor during Labor, caesarean delivery for fetal distress, newborn APGAR at 1 minute $<7$, NICU admission and newborn mortality ('p' value $<0.00001$ ) (Table 2).

The rate of intervention during Labor (instrumental vaginal delivery/ caesarean) increases as NST changes from Cat.-I to Cat.-III, hence NST can detect fetuses at risk early, which can be saved by proper intervention on time (Table3). In a similar study by Rahman $\mathrm{H}$ et al. ${ }^{19}$ Cat.-I had $11 \%$ intervention, Cat.-II had $39 \%$ needed intervention, and Cat.-III had $86 \%$ needed intervention (LSCS). In the study Sandhu et al, $15 \%$ intervention in Cat.-I NST $55 \%$ intervention in Cat.-II and $73 \%$ intervention in Cat.-III NST. ${ }^{24}$ Similarly in the study by Shrestha $\mathrm{P}$ et al fetal distress was more in Cat.-II and Cat.-III, hence needed more intervention. ${ }^{18}$ Patients who 
underwent LSCS (51), 85\% had NST of Cat.-II and Cat.III. In a similar study by Rahman $\mathrm{H}$ et al, incidence of Cat.-I NST 77\%, Cat.-II $14.4 \%$ and Cat.-III NST $8.7 \%$. Also in the study by Lohana RU et al there were more operative deliveries in non-reactive NST group alongwith poor outcome in terms of meconium stained liquor; APGAR score $<7$ at 5 minutes and NICU admission. ${ }^{19,17}$

All 3 study variable (NST, AFI and color of liquor) are good predictor of healthy fetus in pregnancies between 37-41.6 weeks and probability of adverse outcome such as operative delivery and poor APGAR score increases with oligohydramnios, pathological NST and meconium stained liquor (Table 4).

\section{CONCLUSION}

In present study results show that decreased AFI, pathological NST at admission, meconium stained liquor during labor are associated with more caesarean deliveries for fetal distress and poor perinatal outcome (APGAR <7 AT 1min,NICU admission).

SO NST, AFI and color of liquor can effectively detect fetal distress already present at admission, thereby avoiding unnecessary delay and decrease in decision to delivery time and improve fetal outcome.

Therefore AFI, NST and color of liquor-all three together can be used as an important non-invasive method to diagnose fetal compromise already present at the time of admission and obstetricians can be more vigilant by doing intermittent/continous EFM. By doing these three simple tests load of continuous monitoring can be decreased in low resource settings and improving fetal outcome.

\section{Funding: No funding sources}

Conflict of interest: None declared

Ethical approval: The study was approved by the Institutional Ethics Committee

\section{REFERENCES}

1. Policy statement: task force on cerebral palsy and neonatal asphyxia of the society of obstetricians and gynecologists of Canada. J Soc Obstet Gynecol Can.1996;1267-1279

2. Lennan M. A template for defining a causal relationship between acute intrapartum events and cerebral palsy: international consensus statement. British Med J. 1999;319:1054-9.

3. Sinai VT, Arulkumaran S. Arias' practical guide to high-risk pregnancy and delivery, a South Asian Perspective. Available at http:// www.jogc.com /article/S0849-5831(16)30890-4/pdf 359. Accessed on 12 February 2012.

4. Eerden PV, Peter S. Bernstein, neonatal encephalopathy and cerebral palsy: defining the pathogenesis and pathophysiology. Am College Obst Gyne. 2003;8(2).

5. Penna L. Fetal surveillance in labor. In :Arulkumaran S, Regan L, Papageorghiou AT, Monga A, Farquharson, eds. Chapter 10.7 in Oxford desk Ref Obs \& Gyne. Oxford University Press;2011.

6. Phelan JP, Smith CV, Broussard P. Amniotic fluid volume assessment with four quadrant technique at 36-42 weeks gestation. J Reprod Med. 1987;32:540.

7. Winter TC, Roger SC. Clinical sonography: A practical guide hagerstown, MD: Lippincott Williams and Wilkins. 2006:502.

8. Callen PW. Amniotic fluid volume; its role in fetal health and disease. In ultrasonography in Obstetrics and Gynecol, 5th ed. Philadelphia, Saunders Elsevier. 2008:764.

9. Modena AB, Fieni S. Amniotic fluid dynamics. Acta Bio Medica Ateneo Parmanese. 2004;75(1):11.

10. Royal College of Obstetricians and Gynecologists. Evidence based Clinical Guideline no.8,2001.The use and interpretation of CTG in intrapartum fetal surveillance. RCOG Press. London.

11. Schultz M. San Francisco, Calif: The significance of the passage of meconium during labor. Am J Obstet Gynecol. 1924;8:288.

12. ACOG Practice Bulletin No.106:Intrapartum fetal heart rate monitoring :nomenclature, interpretation and general management principles. American College of Obstetricians and Gynecologists. Obstet Gynecol. 2009;114:1191-3.

13. Magann EF, Sanderson M, Martin JN. The amniotic fluid index, single deepest pocket and two-diameter pocket in normal human pregnancy. Am $\mathrm{J}$ Obstet Gynecol. 2000;182:1581.

14. Tasneem SA, Ali MK, Qushnood F. A study of amniotic fluid index in term pregnancy. Int J Curr Res Aca Rev. 2014:2(1):147-52.

15. Bhagat M, Chawla J. Correlation of amniotic fluid index with perinatal outcome. Rev Bras Ginecol Obstet. 2013;35(8):342-8.

16. Alchalabi HA, Obeidat BR, Jallad MF, Khader YS. Induction of labor and perinatal outcome: the impact of the amniotic fluid index. Am J Obstet Gynecol. 2005;192(6):1803-9.

17. Lohana RU, Khatri M, Hariharan C. Correlation of non-stress test with fetal outcome in term pregnancy (37-42 weeks). Int J Reprod Contrac Obst Gynae. 2013:2(4):639-45.

18. Shrestha P, Misha M, Shrestha S. A prospective study on impact of non-stress test in prediction of pregnancy outcome. Am J Public Health Res. 2015;3(4):45-8.

19. Rahman H, Renjhen P, Dutta S. Reliability of admission cardiotocography for intrapartum monitoring in low resource setting. Cochrane Database Syst Rev. 2012;12:CD007863.pub3

20. Becker S, Solomayer E, Dogan C, Wallwiener D, Fehm T. Meconium stained amniotic fluid- perinatal outcome and obstetrical management in a low risk 
suburban population. Am J Obstet Gynecol 2001;185 (4):863-8.

21. Ziadeh SM, Sunna E. Obstetric and perinatal outcome of pregnancies with term labor and meconium stained amniotic fluid. Eur J Obstet Gynecol Reprod Biol. 1998;80(2):169-73.

22. Maymon E, Chaim W, Furman B, Ghezzi F, Shoham Vardi I, Mazor M. Meconium stained amniotic fluid in very low risk pregnancies at term gestation. Gynecol Obstet Invest. 1998;45(1):19-23.
23. Nathan L, Leveno KJ, Carmody TJ, Kelly MA, Sherman ML. Meconium: a 1990 perspective on an old obstetric hazard. Gynecol Obstet Invest. 1994;37(2):91-5.

24. Sandhu GS, Raju R, Bhattacharyya TK, Shaktivardhan. Admission cardiotocography screening of high risk obstetric patients: Med J Armed Forced India. 2008;64(1);43-5.

Cite this article as: Anand RS, Singh P, Sangal R, Srivastava R, Sharma NR, Tiwari HC. Amniotic fluid index, non-stress test and color of liquor: as a predictor of perinatal outcome. Int J Reprod Contracept Obstet Gynecol 2016;5:3512-7. 